\title{
SUBSTRATO ENRIQUECIDO COM CASCA DE PEQUI MELHORA A QUALIDADE DE MUDAS DE BRÓCOLIS E COUVE-FLOR
}

\author{
Rodrigo Amato Moreira ${ }^{1}$, Carlos Alberto Barbosa Galiza², Renata Amato Moreira ${ }^{3}$, Nelson Licínio \\ Campos de Oliveira ${ }^{4}$ \\ ${ }^{1}$ Professor, Doutor em Agronomia, Instituto Federal do Norte de Minas Gerais (IFNMG), Fazenda São Geraldo, S/N. Km 06. Bom \\ Jardim, Januária, MG, CEP 39480-000. \\ ${ }^{2}$ Graduando em Agronomia, Instituto Federal do Norte de Minas Gerais (IFNMG), Bom Jardim, Januária, MG \\ ${ }^{3}$ Doutoranda em Agronomia, Departamento de Agricultura, Universidade Federal de Lavras (UFLA), Lavras, MG. \\ ${ }^{4}$ Professor, Doutor em Agronomia, Instituto Federal do Norte de Minas Gerais- (IFNMG), Bom Jardim, Januária, MG \\ Autor para correspondência: Rodrigo Amato Moreira, rodrigo.moreira@ifnmg.edu.br
}

RESUMO: No Norte de Minas há uma grande produção de pequi (Caryocar brasiliens Cambi), no qual a parte comercializada é somente a semente com a polpa (caroço), com isso grande quantidade de casca é gerada e descartada. Diante deste fato, o trabalho foi realizado no intuito de aproveitar estes resíduos para elaborar substratos para produção de mudas de hortaliças, minimizando custos devido à facilidade de obtenção desse material. O presente experimento foi conduzido com objetivo de avaliar a influência dos diferentes substratos no índice de velocidade de emergência (IVE), facilidade de retirada da plântula da célula e crescimento das mudas de brócolis e couve-flor. A semeadura foi realizada em bandejas de poliestireno expandido com 72 células, preenchidas com os substratos de acordo com o tratamento. Foram utilizadas três sementes para cada célula. Após a germinação e aparecimento da primeira folha verdadeira as plântulas foram desbastadas, permanecendo apenas uma por célula. $O$ experimento foi conduzido em esquema fatorial $2 \times 4$, sendo duas espécies (couve-flor e brócolis) e os quatro tipos de substratos [húmus de minhoca, substrato enriquecido com casca de pequi, substrato comercial (Bioplant $\circledast$ ), substrato enriquecido com casca do pequi + solo, na proporção 1:1], em delineamento de blocos casualizados, com quatro repetições. Cada parcela experimental foi constituída de 12 células. O substrato enriquecido com casca de pequi apresentou características positivas quanto à composição de macro e micronutrientes, reação $\mathrm{C} / \mathrm{N}$ e matéria orgânica. Além disso, influenciou de forma positiva o crescimento das mudas de couve-flor e brócolis. Para brócolis o índice de velocidade de emergência não houve diferença entre os substratos, entretanto para couve-flor a mistura de 1:1 do substrato enriquecido com casca do pequi + solo foi inferior aos demais substratos. O substrato enriquecido com casca de pequi promoveu o maior crescimento e facilidade de remoção da célula das mudas de couve-flor e de brócolis.

PALAVRAS-CHAVE: Brassica oleracea var. itálica, Brassica oleracea var. botrytis, Caryocar brasiliens, Mudas de hortaliças

\section{SUBSTRATE ENRICHED WITH PEQUI PEEL IMPROVES QUALITY OF CAULIFLOWER AND BROCCOLI SEEDLINGS}

\begin{abstract}
In the north of Minas Gerais, Brazil, there is a large production of pequi (Caryocar brasiliens Cambi), which the marketed part is only the seed with pulp, so large amount of peel is generated and discarded. Thus, this research was conducted to use these residues to enrich substrates for use in the production of vegetable seedlings, minimizing costs due to the ease of obtaining such material. The present experiment was carried out with the objective of evaluating the influence of different substrates in the speed index emergence, facility of cell seedling removal and growth of broccoli and cauliflower seedlings. Sowing was performed in expanded polystyrene tray with 72 cells, that was filled with substrates according to the treatment. Three seeds were sowed in each cell. After seed germination and appearance of the seedlings' first leaf, they were thinned, lefting only one per cell. The experiment was conducted in a $2 \times 4$ factorial scheme, with two species (cauliflower and broccoli) and four substrates [vermicompost, commercial substrate (Bioplant $\left.{ }^{\circledR}\right)$, substrate enriched with pequi peel + soil, 1:1 ratio] in randomized block design, with four blocks. Each experimental plot consisted of 12 cells. The substrate enriched with pequi peel showed positive characteristics in terms of macro and micronutrient composition, $\mathrm{C} / \mathrm{N}$ relation and organic matter. In addition, it positively influenced the growth of cauliflower and broccoli seedlings. For broccoli the emergence speed index was not different among the different substrates, however for cauliflower the substrate enriched with pequi peel + soil was lower than the other substrates. The substrate enriched with pequi peel promoted the greatest growth and facility of removal of the cauliflower and broccoli seedlings from cells.
\end{abstract}

KEYWORDS: Brassica oleracea var. itálica, Brassica oleracea var. botrytis, Caryocar brasiliense, Vegetables seedling 


\section{INTRODUÇÃO}

Brócolis (Brassica oleracea var. italica) e couve-flor (Brassica oleracea var. botrytis) são olerícolas pertencentes à família Brassicaceae, muito difundidas no Brasil devido sua grande aceitabilidade e consumo, tornando-se assim de grande importância econômica. A demanda por estas hortaliças têm sido reforçada pela busca de alimentos mais saudáveis, favorecendo também o crescimento da venda do produto fresco.

Devido à produção crescente de hortaliças é fundamental a melhoria no rendimento das culturas, visando inovar em tecnologias de produção para tentar suprir as necessidades e que essas sejam ao mesmo tempo acessíveis a condições econômicas dos produtores. A base da olericultura moderna é a produção de mudas de alta qualidade, uma etapa importante, pois uma muda má formada reduz o desenvolvimento da hortaliça, aumenta o ciclo e acarreta perdas na produção (Echer et al., 2007).

$\mathrm{Na}$ escolha de um substrato para produção de mudas, deve-se observar, principalmente, as características físicas, químicas, biológicas e sanitárias, para promover eficiência na germinação e emergência de plantas. Ainda cabe ressaltar que o substrato deve fornecer nutrientes e oxigênio, ter baixo custo de aquisição ou disponibilidade de material para produção (Steffen et al., 2010; Lopes et al., 2012; Mesquita et al., 2012).

Diante da necessidade de substratos de baixo custo, é crescente a procura por materiais alternativos a serem utilizados para o cultivo de mudas e plantas, grande parte desses são resíduos orgânicos, que podem fornecer os nutrientes necessários ao desenvolvimento das plantas.

O pequizeiro (Caryocar brasiliens Cambi) produz um fruto que é amplamente difundido no bioma cerrado, é utilizado na culinária regional para fabricações de pratos, extração de óleos, produção de fármacos e licores (Santos et al., 2013; Costa et al., 2017). Isso faz com que o pequi desempenhe uma grande importância socioeconômica, pois é uma espécie de base econômica extrativista que alimenta diversas famílias e possibilita alternativas de renda tanto para o meio rural quanto para o meio urbano, pois é um produto que é bastante comercializado no período da safra (Oliveira et al., 2009).

Como a parte de valor econômico do pequi é somente o caroço (semente com a polpa), grande quantidade de cascas é descartada ocasionando grande acúmulo deste resíduo. Deste modo, percebe-se que são importantes estudos científicos sobre a possibilidade de utilização da casca do fruto do pequizeiro na produção de substratos orgânicos.

Além disso, a formulação de substratos pelos produtores com esse tipo de material é mais barata do que adquirir os substratos comerciais. Nesse contexto, resultados positivos da utilização da casca de pequi na formulação de substratos para produção de mudas de tomate e pimentão já foram constatados (Maciel et al., 2017).

Diante do exposto, o trabalho foi realizado com objetivo de avaliar a influência dos diferentes substratos no índice de velocidade de emergência, facilidade de retirada da plântula da célula e crescimento das mudas de brócolis e couve-flor.

\section{MATERIAL E MÉTODOS}

O experimento foi conduzido em viveiro telado de produção de mudas com tela de sombreamento de $50 \%$ no Campus do Instituto Federal do Norte de Minas Gerais, situado no município de Januária, Minas Gerais (latitude: $15^{\circ} 27^{\prime} \mathrm{S}$, longitude: $44^{\circ} 22^{\prime} \mathrm{W}$, altitude de $481 \mathrm{~m}$ ). As principais características climatológicas da região são dadas por forte insolação, temperaturas relativamente altas e regime de chuvas marcado pela escassez, irregularidade e concentração das precipitações em um curto período, em média de três meses. A temperatura máxima atinge $38^{\circ} \mathrm{C}$, a mínima $12,6^{\circ} \mathrm{C}$, a média anual oscila entre $26^{\circ} \mathrm{C}$ e $30^{\circ} \mathrm{C}$ e a precipitação anual média de $939,4 \mathrm{~mm}$ (INMET, 2019).

As cascas de pequi foram coletadas no mercado municipal de Januária-MG. Posteriormente, as cascas foram cortadas em pedaços menores e colocadas para secar à sombra, até chegar ao ponto de desidratação, em seguida o tamanho foi reduzido com o auxílio de um triturador de resíduos orgânicos para acelerar o processo de compostagem.

O composto foi preparado em pilhas constituídas de camadas de casca do pequi, esterco bovino, plantas de mamona, palha de capim forrageiro triturado, respectivamente nas proporções de 2:1:1:1. Após duas semanas da montagem o composto foi revirado com finalidade de ativar o processo de decomposição, possibilitando que os microrganismos fizessem a degradação desejada para o composto orgânico.

Posteriormente, o revolvimento foi realizado a cada semana, sempre se dando cuidado a manter o teor de umidade entre 55 a $60 \%$, na fase inicial da decomposição, e reduzindo-se para $30 \%$ na fase final de estabilização. Em relação a temperatura não foi permitido que ultrapassasse $65^{\circ} \mathrm{C}$.

O composto ficou pronto quando apresentou as seguintes características: temperatura ambiente mesmo após ser revolvido, coloração escura, cheiro de terra, volume reduzido à metade ou a um terço do composto inicial. Esse composto foi utilizado na elaboração de substratos conforme os tratamentos. 
O experimento foi conduzido em esquema fatorial $2 \times 4$, sendo duas espécies [couve-flor 'Quatro Estações' (Brassica oleracea var. italica) e brócolis 'Piracicaba Precoce' (Brassica oleracea var. botrytis)] e quatro substratos [substrato enriquecido com casca de pequi e solo (na proporção 1:1), substrato enriquecido com casca de pequi, composto comercial Bioplant $\AA^{\circledR}$ e húmus de minhoca], em delineamento de blocos ao acaso com quatro repetições. Cada parcela experimental foi constituída de 12 células. As análises físicoquímicas dos substratos foram feitas pelo Laboratório da Empresa Campo, Paracatu, MG.

A semeadura foi realizada em bandejas de poliestireno expandido com 72 células, preenchidas com os substratos de acordo com o tratamento. Foram utilizadas três sementes para cada célula. Após a germinação e aparecimento da primeira folha verdadeira as plântulas foram desbastadas, permanecendo apenas uma por célula.

A irrigação foi manual, realizada duas vezes por dia, com a utilização de regador com crivo fino afim manter a umidade adequada do substrato, da mesma maneira em todos os substratos.

O índice de velocidade de emergência (IVE) foi avaliado pelas contagens diárias das plântulas emergidas conforme a metodologia recomendada por Maguire (1962): IVE $=\mathrm{E} 1 / \mathrm{N} 1+\mathrm{E} 2 / \mathrm{N} 2+\ldots$ $\mathrm{En} / \mathrm{Nn}$. Na qual, IVE = índice de velocidade de emergência; $E 1, E 2, \ldots E n$ = número de plântulas normais computadas na primeira contagem, na segunda contagem e na última contagem e N1,
$\mathrm{N} 2, \ldots \quad \mathrm{Nn}=$ número de dias da semeadura à primeira, segunda e última contagem.

Ao final do experimento (30 dias após a semeadura) foi avaliada a facilidade de retirada da muda da célula e agregação do substrato às raízes. Para tal, foi utilizada uma escala de um a três, na qual 1 (um) representa a máxima dificuldade de retirada ou esboroamento máximo dos torrões que compõem a célula, 2 (dois) representa dificuldade intermediária para a retirada ou esboroamento mediano e 3 (três) denota a máxima facilidade na retirada e apresenta o torrão da célula íntegro (Correia et al., 2003).

Foram avaliados também a massa fresca foliar e a radicular $(\mathrm{mg})$ através de balança de precisão. As massas secas foram obtidas após a secagem por $48 \mathrm{~h}$ em estufa com circulação forçada de ar a $65^{\circ} \mathrm{C}$.

Os dados obtidos foram submetidos à análise de variância e as médias agrupadas pelo teste de Scott-Knott a $5 \%$ de probabilidade utilizando o programa estatístico SISVAR (Ferreira, 2011).

\section{RESULTADOS E DISCUSSÃO}

Com base na análise físico-química dos substratos (Tabela 1), foram observados resultados satisfatórios na relação $\mathrm{C} / \mathrm{N}$ para $\mathrm{o}$ substrato enriquecido com a casca de pequi, com valor de 12,69/1, comprovando que o composto já estava estabilizado. Entretanto para o substrato comercial Bioplant ${ }^{\circledR}$ foi verificada uma relação $\mathrm{C} / \mathrm{N}$ alta, superior a $37 / 1$.

Tabela 1. Características físico-químicas dos diferentes substratos utilizados na produção de brócolis e couve-flor. IFNMG, campus Januária, 2019.

\begin{tabular}{ccccc}
\hline & \multicolumn{5}{c}{ Substratos } \\
Características & 1 & 2 & 3 & 4 \\
\hline Umidade (\%) & 20,6 & 10,6 & 37,7 & 34,2 \\
Matéria Orgânica (\%) & 35,3 & 13,6 & 20,6 & 32,5 \\
Carbono Orgânico Oxidável (\%) & 20,46 & 7,87 & 11,94 & 18,83 \\
pH em CaCl & 7,57 & 7,25 & 6,18 & 5,32 \\
Relação C/N & 12,79 & 10,22 & 13,12 & $>37,66$ \\
$\mathrm{~N}(\%)$ & 1,6 & 0,77 & 0,91 & $<0,50$ \\
$\mathrm{P}(\%)$ & 1 & $<1$ & $<1$ & $<1$ \\
$\mathrm{~K}(\%)$ & 1,8 & $<1$ & $<1$ & $<1$ \\
$\mathrm{Mg}(\%)$ & $<0,5$ & $<0,5$ & $<0,5$ & 0,77 \\
$\mathrm{~B} \mathrm{( \% )}$ & $<0,1$ & $<0,1$ & $<0,1$ & $<0,1$ \\
$\mathrm{Cu}(\%)$ & $<0,05$ & $<0,05$ & $<0,05$ & $<0,05$ \\
$\mathrm{Mn}(\%)$ & $<0,05$ & $<0,05$ & $<0,05$ & $<0,05$ \\
$\mathrm{Ca}(\%)$ & 1,63 & 0,54 & 1,75 & 0,96 \\
$\mathrm{Fe}(\%)$ & 0,24 & 0,6 & 0,3 & 0,96 \\
$\mathrm{~S}(\%)$ & $<1,0$ & $<1,0$ & $<1,0$ & $<1,0$ \\
$\mathrm{Zn}(\%)$ & $<0,05$ & $<0,05$ & $<0,05$ & $<0,05$ \\
\hline
\end{tabular}

Substratos: $1=$ Substrato enriquecido com casca de pequi, $2=$ Substrato enriquecido com casca de pequi + solo, $3=$ Húmus de minhoca, $4=$ substrato comercial Bioplant ${ }^{\circledR}$. 
Vale ressaltar, que a relação inicial ideal para a maioria dos substratos deve-se situar próximo de $30 / 1$. Já no produto final a relação $\mathrm{C} / \mathrm{N}$ estabelece entre valores de 10/1 e 20/1 (Fernandes e Silva, 1999).

Em relação à matéria orgânica do substrato enriquecido com a casca do pequi foi constatado valor de $35,3 \%$, o maior entre os substratos utilizados. Assim, essa característica permitiu que o composto tivesse melhor desempenho na retenção de água, porosidade e disponibilidade de nutrientes para o desenvolvimento das plântulas.

O substrato enriquecido com casca de pequi também apresentou características químicas satisfatórias, com $\mathrm{K}, \mathrm{Ca}, \mathrm{N}$ e $\mathrm{P}$ em maiores percentuais entre os macronutrientes com $1,8 \%$, $1,63 \%, 1,6 \%$ e $1,0 \%$ respectivamente (tabela 1 ). Já para aos micronutrientes, foi observada a presença de $\mathrm{Mn}, \mathrm{B}, \mathrm{Cu}$, e Fe no composto enriquecido com casca de pequi.

Ao avaliar o potencial do composto orgânico produzido a partir da casca de pequi na produtividade do tomate cereja, Silva et al. (2019) observaram na análise química que o $\mathrm{N}$ se destacou entre os macronutrientes seguido do $\mathrm{Ca}$. $\mathrm{Em}$ relação aos micronutrientes, o $\mathrm{Mn}$ e o $\mathrm{Fe}$ estavam em maior quantidade, possibilitando a utilização do composto na produção de mudas.
Diante da análise química dos diferentes substratos avaliados nesse experimento, fica evidente que o substrato enriquecido com casca de pequi pode ser utilizado na produção de mudas de couve-flor e brócolis, visto que apresentou boas características físicas e os principais nutrientes $(\mathrm{N}$, $P$ e K) requeridos para o bom desenvolvimento das hortaliças (Filgueira, 2008).

$\mathrm{O} \mathrm{N}$ e $\circ \mathrm{K}$ estão entre os nutrientes mais requeridos pelas culturas, sendo que a deficiência de $\mathrm{N}$ em mudas compromete o desenvolvimento e reduz o acúmulo de matéria seca (Higuti, et al. 2010). O P é o elemento-chave na fase inicial de crescimento devido ao maior acúmulo de biomassa, pois contribui diretamente com a fotossíntese, e está relacionado a diversas atividades bioquímicas, tais como ativador de grande número de enzimas, regulador da pressão osmótica, abertura e fechamento dos estômatos (Godoy et al., 2012).

Os diferentes substratos influenciaram as massas frescas e secas da parte aérea e da raiz, bem como no índice de velocidade de emergência das mudas de couve-flor e do brócolis (Tabela 2). Sendo que o substrato enriquecido com casca de pequi proporcionou médias maiores para essas variáveis analisadas (Tabelas 3 e 4).

Tabela 2. Resumo da análise de variância para as características agronômicas de matéria seca de parte aérea (MSPA), matéria seca da raiz (MSR), matéria fresca de parte aérea (MFPA), matéria fresca da raiz (MFR) e índice de velocidade de emergência (IVE), de mudas de brócolis e couve-flor com os diferentes substratos. IFNMG, campus Januária, 2019.

\begin{tabular}{ccccccc}
\hline & & \multicolumn{5}{c}{ QM } \\
\cline { 3 - 7 } FV & GL & MSPA & MSR & MFPA & MFR & IVE \\
\hline Espécie & 1 & $19353.80^{*}$ & $49.50^{\text {NS }}$ & $407930.28^{*}$ & $383250.12^{*}$ & $2579.03^{*}$ \\
Substrato & 3 & $50063.42^{*}$ & $34742.68^{*}$ & $1357533.86^{*}$ & $335584.08^{*}$ & $72.87^{*}$ \\
Esp*Subst & 3 & $3457.79^{*}$ & $4355.25^{*}$ & $150208.94^{*}$ & $74690.70^{*}$ & $43.13^{*}$ \\
\hline CV (\%) & - & 17,5 & 32,8 & 21,9 & 25,75 & 33,9 \\
\hline NS - não significativo, ${ }^{*}$ significativo a $5 \%$ de probabilidade pelo teste F.
\end{tabular}

Tabela 3. Médias das características agronômicas de matéria seca de parte aérea (MSPA), matéria seca da raiz (MSR), matéria fresca de parte aérea (MFPA), matéria fresca da raiz (MFR) e índice de velocidade de emergência (IVE), avaliadas na produção de mudas de couve-flor em diferentes substratos ( $1=$ substrato enriquecido com casca de pequi, $2=$ húmus de minhoca, 3 = substrato enriquecido com casca de pequi + solo e 4 = substrato comercial Bioplant $\left.\AA^{\circledR}\right)$. IFNMG, campus Januária, 2019.

\begin{tabular}{cccccc}
\hline Substrato & MSPA $(\mathrm{mg})$ & MSR $(\mathrm{mg})$ & MFPA(mg) & MFR $(\mathrm{mg})$ & IVE \\
\hline 1 & $229,00 \mathrm{a}$ & $180,00 \mathrm{a}$ & $1020,25 \mathrm{a}$ & $759,00 \mathrm{a}$ & $18,15 \mathrm{a}$ \\
2 & $152,75 \mathrm{~b}$ & $160,50 \mathrm{a}$ & $748,00 \mathrm{~b}$ & $523,00 \mathrm{~b}$ & $24,74 \mathrm{a}$ \\
3 & $160,75 \mathrm{~b}$ & $149,00 \mathrm{a}$ & $528,25 \mathrm{c}$ & $316,75 \mathrm{c}$ & $12,23 \mathrm{~b}$ \\
4 & $27,58 \mathrm{c}$ & $25,45 \mathrm{~b}$ & $27,00 \mathrm{~d}$ & $90,00 \mathrm{~d}$ & $21,47 \mathrm{a}$ \\
\hline CV $(\%)$ & 17,5 & 32,8 & 21,9 & 25,75 & 33,9
\end{tabular}

*Médias seguidas de mesma letra na coluna não diferem entre si pelo teste Scott-Knott ao nível de $5 \%$ de probabilidade. 
Tabela 4. Médias das características agronômicas de matéria seca de parte aérea (MSPA), matéria seca da raiz (MSR), matéria fresca de parte aérea (MFPA), matéria fresca da raiz (MFR) e índice de velocidade de emergência (IVE), avaliadas na produção de mudas de brócolis em diferentes substratos ( $1=$ substrato enriquecido com casca de pequi, 2 = húmus de minhoca, 3 = substrato enriquecido com casca de pequi + solo e 4 = substrato comercial Bioplant $\left.{ }^{\circledR}\right)$. IFNMG, campus Januária, 2019.

\begin{tabular}{cccccc}
\hline Substrato & MSPA $(\mathrm{mg})$ & MSR $(\mathrm{mg})$ & MFPA $(\mathrm{mg})$ & MFR $(\mathrm{mg})$ & IVE \\
\hline 1 & $207,00 \mathrm{a}$ & $151,00 \mathrm{a}$ & $1012,00 \mathrm{a}$ & $272,00 \mathrm{a}$ & $1,10 \mathrm{a}$ \\
2 & $77,00 \mathrm{~b}$ & $209,75 \mathrm{a}$ & $263,50 \mathrm{~b}$ & $372,00 \mathrm{a}$ & $2,08 \mathrm{a}$ \\
3 & $68,00 \mathrm{~b}$ & $96,25 \mathrm{~b}$ & $88,25 \mathrm{c}$ & $110,00 \mathrm{~b}$ & $0,33 \mathrm{a}$ \\
4 & $21,33 \mathrm{c}$ & $48,00 \mathrm{~b}$ & $56,50 \mathrm{c}$ & $59,25 \mathrm{~b}$ & $1,26 \mathrm{a}$ \\
\hline CV (\%) & 17,5 & 32,8 & 21,9 & 25,75 & 33,9 \\
\hline
\end{tabular}

*Médias seguidas de mesma letra na coluna não diferem entre si pelo teste Scott-Knott ao nível de 5\% de probabilidade.

O bom desenvolvimento da parte aérea, especialmente do número de folhas e 0 comprimento da raiz, são os parâmetros mais importantes no cultivo de mudas, pois são responsáveis pela fotossíntese e absorção de nutrientes, por isso é imprescindível o uso de um bom substrato na fase de produção de mudas.

Resultados semelhantes foram obtidos por Furlan et al. (2007) que verificaram que o uso dos compostos orgânicos na produção de mudas de couve-folha foi superior em relação ao substrato comercial Bioplant $\AA$, pois, além de promoverem melhoria nas variáveis analisadas, representaram diminuição nos custos de produção de mudas.

Também já foi verificado que substratos a base de pequi proporcionam bom desenvolvimento de mudas de tomate e pimentão (Maciel et al., 2017), pois a adição de matéria orgânica aumenta a concentração de nutrientes disponíveis para as plantas, fazendo que as mesmas se desenvolvam com maior vigor (Milec, 2007).

Em relação ao índice de velocidade de emergência não foi observada influência dos substratos para as mudas de brócolis, já para as mudas da couve-flor foi notada diferença (tabelas 3 e 4). O substrato enriquecido com casca de pequi + solo, na proporção 1:1, proporcionou o menor IVE comparado com os outros substratos. Isso pode ser explicado devido a esse substrato conter menos resíduos orgânicos na composição e assim contribuir sensivelmente com menor aeração, menor capacidade de retenção de água e consequente menor velocidade de germinação.

Foi constatado durante a execução do experimento, que a mistura do composto enriquecido com caca de pequi + solo, não ofereceu uma aeração adequada para a germinação das sementes, uma vez que houve dificuldade de infiltração de água nas parcelas, indicando reduzida porosidade. Ao avaliar produção de mudas de pimentão, Santos et al. (2010) também observaram que substratos com baixa aeração podem reduzir o percentual de emergência e o IVE.

Os substratos utilizados no experimento proporcionaram resultados diferentes na facilidade da retirada da muda da célula (Tabela 5). Para ambas as culturas, o substrato enriquecido com casca de pequi apresentou a melhor facilidade de retirada da célula e torrões íntegros. Para brócolis, o húmus de minhoca também apresentou ótima facilidade na retirada da célula. Maciel et al. (2017) também observaram que o composto à base de pequi promoveu facilidade de retirada das plantas das células e agregação dos substratos às raízes de tomate.

Tabela 5. Características dos diferentes substratos na avaliação de Facilidade de retirada das mudas de couve-flor e brócolis das células em diferentes substratos ( $1=$ substrato enriquecido com casca de pequi, 2 = húmus de minhoca, 3 = substrato enriquecido com casca de pequi + solo e $4=$ substrato comercial Bioplant $\left.{ }^{\circledR}\right)$. IFNMG, campus Januária, 2019.

\begin{tabular}{ccc}
\hline Substrato & Couve-flor & Brócolis \\
\hline 1 & 3 & 3 \\
2 & 2 & 3 \\
3 & 2 & 2 \\
4 & 1 & 1 \\
\hline
\end{tabular}

*Para facilidade de retirada da muda da célula e agregação do substrato às raízes atribuíram-se notas: 1 (difícil ou ruim), 2 (fácil ou boa) e 3 (muito fácil ou ótima), respectivamente.

Vale ressaltar que para o substrato comercial Bioplant ${ }^{\circledR}$ foi atribuído a nota ruim ou difícil (Tabela 5), em decorrência do baixo crescimento do sistema radicular, ao qual não preencheu a totalidade do espaço da célula e ocorreu o esboroamento dos torrões quando retirados.

Essa característica de facilidade de retirada das mudas das células deve ser levada em conta na escolha do substrato, pois promoverá menor 
estresse no transplante e melhor pegamento das mudas no campo.

Sendo assim, o substrato enriquecido com casca de pequi promoveu o maior crescimento e facilidade de remoção da célula das mudas de couve-flor e de brócolis.

\section{REFERÊNCIAS}

Echer, M. M.; Guimarães, V. F.; Aranda, A. N.; Bortolazzo, E. D.; Braga, J. S. Avaliação de mudas de beterraba em função do substrato e do tipo de bandeja. Semina: Ciências Agrárias, 2007, 28, 4550 .

Costa A. P. F.; Pinto, E. G.; Soares, D. S. B. Obtenção de farinha do mesocarpo de pequi. Revista Agrarian, 2017, 10, 349-354.

Ferreira, D. F. Sisvar: a computer statistical analysis system. Ciência e Agrotecnologia, 2011, 35, 10391042.

Fernandes, F.; Silva, S. M. C. P. Manual prático para a compostagem de biossólidos. Rio de Janeiro: Associação Brasileira de Engenharia Sanitária e Ambiental, 1999. 84p.

Furlan, F.; Costa, M. S. S. M.; Costa, L. A. M.; Marini, D.; Castoldi, G.; Souza, J. H. Pivetta, L. A.; Pivetta, L. G. Substratos alternativos para produção de mudas de couve folha em sistema orgânico. Revista Brasileira de Agroecologia, 2007, 2, 1686-1689.

Filgueira, F. A. R. Novo manual de olericultura: agrotecnologia moderna na produção e comercialização de hortaliças. 3. ed. rev. e ampl. Viçosa, MG: UFV, 2008. 421 p.

Godoy, A. R.; Salata, A. C.; Cardoso, A. I. I.; Evangelista, R. M.; Kano, C.; Higuti, A. R. O. Produção e qualidade pós-colheita de couve-flor em função de doses de potássio em cobertura. Scientia Agrária Paranaensis, 2012, 11, 33-42.

Higuti, A. R. O; Salata, A. C.; Godoy, A. R.; Cardoso, A. I. I. Produção de mudas de abóbora com diferentes doses de nitrogênio e potássio. Bragantia, 2010, 69, 377-380.

Lopes, J. C.; Mauri, J.; Ferreira, A.; Alexandre, R. S.; Freitas, A. R. Broccoli production depending on the seed production system and organic and mineral fertilizer. Horticultura Brasileira, 2012, 30, 143-150.

Maciel, T. C. M.; Silva, T. I.; Alcantara, F. D. O; Marco, C. A.; Ness, R. L. L. Substrato à base de pequi (Caryocar coriaceum) na produção de mudas de tomate e pimentão. Revista de Agricultura Neotropical, 2017, 4, 9-16.

Mesquita, E. F.; Chaves, L. H. G.; Freitas, B. V.; Silva, G. A.; Sousa, M. V. R.; Andrade, R. Produção de mudas de mamoeiro em função de substratos contendo esterco bovino e volumes de recipientes. Revista Brasileira de Ciências Agrárias, 2012, 7, 5865.

Milec, A. T.; Moraes, R. M. D.; Xavier, V. C.; Conceição; D. C.; Mauch, C. R.; Morselli, T. B. G. A. Produção de mudas de couve brócolis em dois sistemas de irrigação utilizando substratos orgânicos. Cadernos de Agroecologia, 2007, 2, 1483-1486.

Oliveira, M. E. B.; Guerra, N. B.; Maia, A. H. N.; Alves, R. E.; Xavier, D. S.; Matos, N. M. S. Caracterização física de frutos do pequizeiro nativos da chapada do Araripe-CE. Revista Brasileira de Fruticultura, 2009, 26, 572-578.

Santos, M. R.; Sediyama, M. A. N.; Salgado, L. T.; Vidigal, S. M.; Reigado, F. R. Produção de mudas de pimentão em substratos à base de vermicomposto. Bioscience Journal, 2010, 26, 572578.

Santos, F. S.; Santos, R. F.; Dias, P. P.; Zanão Jr, L. A.; Tomassoni, F. A cultura do pequi (Caryocar brasiliense CAMB), Acta Iguazu, 2013, 2, 46-57.

Silva, T. I; Feitosa, A. J. S.; Maciel, T. C. M.; Figueiredo, F. R. A.; Marco, C. A. Produtividade de tomate cereja (Solanum lycopersicon Mill.) em função da adubação orgânica à base de pequi (Caryocar coriaceum Willd Poir.). Acta Iguazu, 2019, 8, 50-59.

Steffen, G. P. K.; Antoniolli, Z. I.; Steffen, R. B.; Machado, R. G. Casca de arroz e esterco bovino como substratos para a multiplicação de minhocas e produção de mudas de tomate e alface. Acta Zoológica Mexicana, 2010, 2, 333-343. 